\title{
Hormone replacement therapy and antidepressant prescription patterns: a reciprocal relationship
}

\author{
Roger S. McIntyre, Jakub Z. Konarski, Sophie Grigoriadis, Nancy C. Fan, Deborah A. Mancini, \\ Kari A. Fulton, Donna E. Stewart, Sidney H. Kennedy
}

M ajor depressive disorder is a prevalent and disabling condition. ${ }^{1}$ The causes of mood disorders are heterogeneous, involving a complicated interplay of both psychosocial and biological variables., ${ }^{2,3}$ In an analysis of adult women, the psychosocial variables that predicted major depression appeared to result from 3 broad pathways reflecting internalizing symptoms, externalizing symptoms and psychosocial adversity. ${ }^{4}$ In addition, there are significant associations between major depressive disorder and many chronic medical conditions (e.g., obesity, diabetes mellitus and hypothyroidism), underscoring the myriad biological variables that may be present in depression. ${ }^{5}$

Sex-related differences in mood disorders have been frequently reported ${ }^{6-9}$ and indicate the relevance of the reproductive endocrine system in the pathogenesis and treatment of mood disorders. For example, exacerbation of depressive symptoms and recurrence of depression in women with multiple-episode depression has been reported during perimenopause..$^{10}$ The salutary neuropsychiatric effects of gonadal steroids are implicated yet not confirmed with extant data. ${ }^{11}$ Although the mechanism by which estrogen might attenuate depressive symptoms is unknown, mounting evidence indicates that estrogen influences neuronal function through monoaminergic- and GABAergicmediated systems. Estrogen is also noted to inhibit monoamine oxidase activity. ${ }^{12-14}$

Preliminary data suggest that hormone replacement therapy (HRT) and antidepressant therapy may have overlapping molecular targets. ${ }^{15-20}$ Moreover, the putative antidepressant effects of HRT have also been reported..$^{11,21-29}$ HRT has been prescribed for climacteric symptoms (e.g., vasomotor symptoms), and some antidepressants (e.g., serotonergic antidepressants) have been shown to alleviate the full range of climacteric symptoms. ${ }^{19,20,30}$ Thus, many women who experience depressive symptoms or a major depressive disorder at the time of menopause may find relief of these symptoms and even the disorder by using HRT.

With the publication in July 2002 of results indicating potential harmful effects of HRT (estrogen monotherapy), there was a dramatic reduction in HRT prescriptions. We hypothesized that the abrupt discontinuation of HRT would be associated with an increase in antidepressant usage. Fig. 1 appears to confirm the hypothesis.

We found that a significant decrease in the number of HRT prescriptions was associated with a statistically significant increase in prescriptions of serotonergic antidepressants. Others have noted associations between changes in HRT and antidepressant prescription patterns. ${ }^{17}$ The simultaneous increase in prescriptions of serotonergic antidepressants suggests that antidepressants are being prescribed for symptoms (psychological, physical) previously controlled with the use of HRT. . $^{192,30}$

With the diminished popularity of HRT, physicians may encounter women who are experiencing depressive symptoms or actual major depressive disorders that worsen at the time of menopause. A thorough assessment is encouraged for women who present during perimenopause with disabling psychological or somatic symptoms. Symptoms indicative of major depression include feelings of hopelessness, helplessness and worthlessness, suicidal ideation and anhedonia.

If patients are found to have major depressive disorder, as defined in the DSM-IV-TR,,$^{31}$ they should be offered pharmacotherapy, psychotherapy or both. If drug therapy is chosen, standard pharmacological agents are recommended, keeping in mind that serotonergic antidepressants are also effective against climacteric symptoms. ${ }^{32} \mathrm{Al}-$ though there is a paucity of randomized controlled trials evaluating depression-specific psychotherapy (e.g., cognitive behavioural therapy) in perimenopausal women, cognitive behavioural therapy has been proven effective in the treatment of major depressive disorder, and it avoids the burden of drug-related adverse events. ${ }^{33}$ The Canadian Psychiatric Association recommends both medication and psychotherapy as first-line treatment of depressive disorders. ${ }^{33}$ Preference for either treatment modality is influenced by the severity of illness, the availability of treatment and patient preference.

In the interim, practitioners are encouraged to be vigilant for breakthrough psychiatric and climacteric symptoms in patients discontinuing HRT and to familiarize themselves with the beneficial effects of serotonergic antidepressants on climacteric symptoms. 

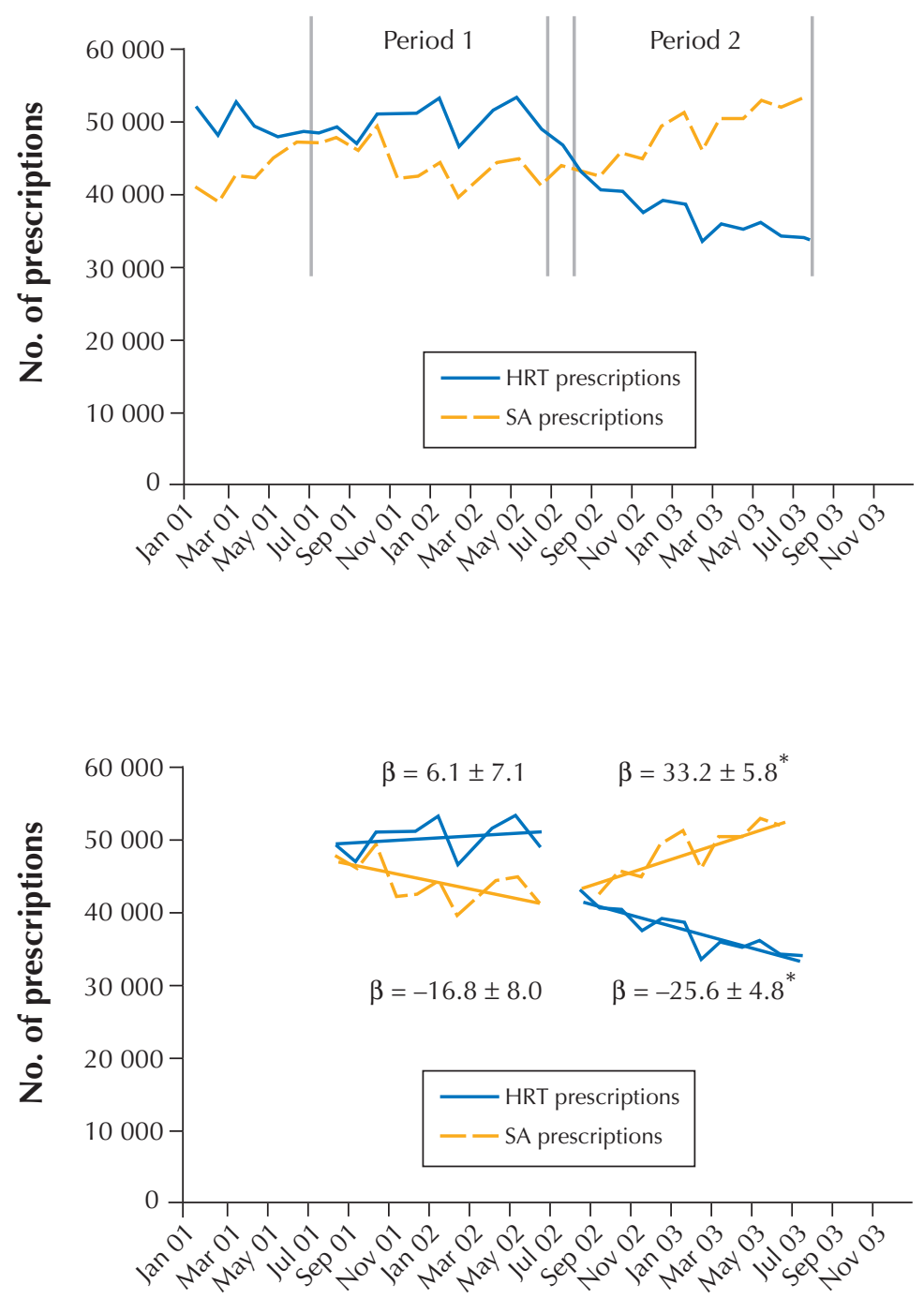

Fig. 1: Top: Total estimated prescriptions dispensed in Ontario for hormone replacement therapy (HRT: oral and transdermal estrogen monotherapy and estrogen-progesterone combination therapy) and serotonergic antidepressants (SAs: citalopram, fluoxetine, sertraline, fluvoxamine, paroxetine, venlafaxine, nefazadone and trazadone) to women 45-65 years old, from January 2001 to June 2003. [Source: IMS Health Canada.] A consistent downward trajectory in the number of HRT prescriptions and a simultaneous increase in the number of SA prescriptions occurred after July 2002, when results indicating potential harmful effects of HRT were published. Bottom: Linear regression models of the number of prescriptions against time, for each prescription type (HRT and SA) and for each time period (11 months before and 11 months after July 2002). The predicted slopes $(\beta \pm$ standard error [prescriptions/day]) are shown, accompanied by a test of the null hypothesis: $\beta=0$. There was no statistically significant longitudinal trend during the 11 months before July 2002; however, during the period following July 2002, there was a statistically significant decrease in HRT utilization that coincided with an increase in SA utilization. Comparison of the regression models (HRT v. SA prescriptions) revealed a statistically significant change in the prescription pattern of both agents after the medical scrutiny of HRT usage $(\beta$ : $-25.6 \mathrm{v}$. 33.2, $p<0.001) .{ }^{*} p<0.001$.
From the University Health Network (McIntyre, Grigoriadis, Fan, Mancini, Fulton, Stewart, Kennedy), and the Department of Psychiatry (McIntyre, Grigoriadis, Stewart, Kennedy) and the Institute of Medical Science (Konarski), University of Toronto, Toronto, Ont

Competing interests: None declared for Jakub Konarski, Nancy Fan, Deborah Mancini or Kari Fulton. Roger McIntyre has received consultant and speaker fees from Astra Zeneca, Eli Lilly, Janssen-Ortho Pharmaceuticals, Organon, Wyeth Pharmaceuticals, Lundbeck, GlaxoSmithKline, ORYX Pharmaceuticals, Biovail Corporation and Pfizer Canada; he has received research funding from Wyeth Pharmaceuticals, GlaxoSmithKline, Merck and Servier. Sophie Grigoriadis has received research funding from Organon Canada, Merck, Eli Lilly and Jansen-Ortho Pharmaceuticals she also received honoraria from Wyeth Pharmaceuticals. Donna Stewart has received research, consultant and speaker fees from Eli Lilly, and consultant and speaker fees from Wyeth Pharmaceuticals. Sidney Kennedy has received research funding from Janssen-Ortho Pharmaceuticals and Eli Lilly, and consultant fees from AstraZeneca, Biovail Corporation, Eli Lilly, Lundbeck, Servier, Wyeth Pharmaceuticals and Boehringer Ingelheim.

Contributors: Roger McIntyre, Jakub Konarski and Kari Fulton contributed to the study conception and design, the data analysis and the manuscript production. Sophie Grigoriadis, Deborah Mancini, Donna Stewart and Sidney Kennedy contributed to the study conception and design and the manuscript production. Nancy Fan contributed to the conception and design of the article. All of the authors gave their final approval of the version submitted for publication.

Acknowledgements: We thank Gary Fabian at IMS Health Canada for providing the prescription data.

\section{References}

1. Canadian Psychiatric Association, Canadian Network for Mood and Anxiety Treatments (CANMAT). Clinical guidelines for the treatment of depressive disorders. Can 7 Psychiatry 2001;46(Suppl 1):5S-90S.

2. Bebbington $\mathrm{P}$, Wilkins $\mathrm{S}$, Sham $\mathrm{P}$, Jones $\mathrm{P}$, van $\mathrm{Os} \mathrm{J}$, Murray R, Toone B, Lewis S. Life events before psychotic episodes: Do clinical and social variables affect the relationship? Soc Psychiatry Psychiatr Epidemiol 1996;31(3-4):122-8.

3. Bebbington P, Dunn G, Jenkins R, Lewis G, Brugha T, Farrell M, Meltzer H. The influence of age and sex on the prevalence of depressive conditions: report from the National Survey of Psychiatric Morbidity. Int Rev Psychiatry 2003;15(1-2):74-83.

4. Kendler KS, Gardner CO, Prescott CA. Toward a comprehensive developmental model for major depression in women. Am $\mathcal{F}$ Psychiatry 2002;159(7):1133-45.

5. Brown ES, Varghese FP, McEwen BS. Association of depression with medical illness: Does cortisol play a role? Biol Psychiatry 2004;55(1):1-9.

6. Altshuler LL. The use of SSRIs in depressive disorders specific to women. 7 Clin Psychiatry 2002;63(Suppl 7):3-8.

7. Kornstein SG, Sloan DM, Thase ME. Gender-specific differences in depression and treatment response. Psychopharmacol Bull 2002;36(4 Suppl 3):99-112.

8. Grigoriadis S, Kennedy SH, Bagby RM. A comparison of antidepressant response in younger and older women. 7 Clin Psychopharmacol 2003;23(4):405-7.

9. Sloan DM, Kornstein SG. Gender differences in depression and response to antidepressant treatment. Psychiatr Clin North Am 2003;26(3):581-94.

10. Burt VK, Altshuler LL, Rasgon N. Depressive symptoms in the perimenopause: prevalence, assessment, and guidelines for treatment. Harv Rev Psychiatry 1998;6(3): 121-32

11. Schmidt PJ, Nieman L, Danaceau MA, Tobin MB, Roca CA, Murphy JH, Rubinow DR. Estrogen replacement in perimenopause-related depression: a preliminary report. Am 7 Obstet Gynecol 2000;183(2):414-20.

12. Kendall DA, Stancel GM, Enna SJ. The influence of sex hormones on antidepressant-induced alterations in neu- 
rotransmitter receptor binding. 7 Neurosci 1982;2(3):354-60.

13. McEwen BS, Alves SE, Bulloch K, Weiland NG. Ovarian steroids and the brain: implications for cognition and aging. Neurology 1997;48(5 Suppl 7):S8-15.

14. Chakravorty SG, Halbreich U. The influence of estrogen on monoamine oxidase activity. Psychopharmacol Bull 1997;33(2):229-33.

15. Halbreich U, Kahn LS. Selective oestrogen receptor modulators--current and future brain and behaviour applications. Expert Opin Pharmacother 2000;1(7): 1385-98.

16. Winterhoff H, Spengler B, Christoffel V, Butterweck V, Lohning A. Cimicifuga extract BNO 1055: reduction of hot flushes and hints on antidepressant activity. Maturitas 2003; 44(Suppl 1):S51-S58

17. Reynolds RF, Walker AM, Obermeyer CM, Rahman O, Guilbert D. Discontinuation of postmenopausal hormone therapy in a Massachusetts HMO. 7 Clin Epidemiol 2001;54(10):1056-64.

18. Weitzner MA, Moncello J, Jacobsen PB, Minton S. A pilot trial of paroxetine for the treatment of hot flashes and associated symptoms in women with breast cancer. 7 Pain Symptom Manage 2002;23(4):337-45.

19. Stoppe G, Doren M. Critical appraisal of effects of estrogen replacement therapy on symptoms of depressed mood. Arch Women Ment Health 2002;5(2):39-47.

20. Stearns V, Beebe KL, Iyengar M, Dube E. Paroxetine controlled release in the treatment of menopausal hot flashes: a randomized controlled trial. $7 A M A$ 2003;289(21):2827-34.

21. Campbell S, Whitehead M. Oestrogens for menopausal flushing. BM7 1977;1 (6053):104-5

22. Bloch M, Schmidt PJ, Danaceau M, Murphy J, Nieman L, Rubinow DR. Effects of gonadal steroids in women with a history of postpartum depression. Am 7 Psychiatry 2000;157(6):924-30.

23. Coope J. Is oestrogen therapy effective in the treatment of menopausal depression? 7 R Coll Gen Pract 1981;31(224):134-40.

24. Pearce J, Hawton K, Blake F, Barlow D, Rees M, Fagg J, Keenan J. Psychological effects of continuation versus discontinuation of hormone replacement therapy by estrogen implants: a placebo-controlled study. 7 Psychosom Res $1997 ; 42(2): 177-86$
25. Smith RN, Studd JW, Zamblera D, Holland EF. A randomised comparison over 8 months of 100 micrograms and 200 micrograms twice weekly doses of transdermal oestradiol in the treatment of severe premenstrual syndrome. $\mathrm{Br}$ 7 Obstet Gynaecol 1995;102(6):475-84.

26. Gregoire AJ, Kumar R, Everitt B, Henderson AF, Studd JW. Transdermal oestrogen for treatment of severe postnatal depression. Lancet 1996;347 (9006):930-3

27. Cohen LS, Soares CN, Poitras JR, Prouty J, Alexander AB, Shifren JL. Shortterm use of estradiol for depression in perimenopausal and postmenopausal women: a preliminary report. Am 7 Psychiatry 2003;160(8):1519-22.

28. Soares CN, Almeida OP, Joffe H, Cohen LS. Efficacy of estradiol for the treatment of depressive disorders in perimenopausal women: a double-blind, randomized, placebo-controlled trial. Arch Gen Psychiatry 2001;58(6):529-34.

29. Rasgon NL, Altshuler LL, Fairbanks L. Estrogen-replacement therapy for depression. Am f Psychiatry 2001;158(10):1738.

30. Pinkerton JV, Santen R. Use of alternatives to estrogen for treatment of menopause. Minerva Endocrinol 2002;27(1):21-41.

31. Diagnostic and statistical manual of mental disorders. 4th ed, text revision. Washington: American Psychiatric Association; 2000.

32. The North American Menopause Society. Treatment of menopause-associated vasomotor symptoms: position statement of The North American Menopause Society. Menopause 2004;11(1):11-33.

33. Thorpe L, Whitney DK, Kutcher SP, Kennedy SH. Clinical guidelines for the treatment of depressive disorders. VI. Special populations. Can 7 Psychiatry 2001;46(Suppl 1):63S-76S.

Correspondence to: Dr. Roger S. McIntyre, Head, Mood

Disorders Psychopharmacology Unit, University Health Network

- Toronto Western Hospital, 399 Bathurst St., Toronto ON

M5T 2S8; fax 416 603-5368; rmcintyr@uhnres.utoronto.ca
CMA CENTRE FOR

PHYSICIAN HEALTH AND WELL-BEING

HEALTHY PHYSICIANS, VIBRANT PROFESSION

\section{If you are feeling}

overwhelmed by

professional and personal

demands, you are not alone.

Research has found

that $45.7 \%$ of

Canadian physicians are

in an advanced

state of burnout.*
CMA believes in a culture of medicine that values the health of its practitioners and does not stigmatize those who seek personal assistance. CMA's Centre for Physician Health and Well-being provides national leadership and advocacy on issues affecting the health and morale of Canadian physicians.

To learn more about the work of the centre or to access information and resources, visit the centre's Web section at cma.ca or call 877 CMA-4-YOU (877 262-4968).

The centre supports and complements the work of the provincial and territorial physician health programs but does not provide individual assessment, support or treatment advice. Contact numbers for the programs are available at cma.ca

*2003 CMA Physician Resource Questionnaire. 